\title{
Pueblos indígenas y el rechazo al mercado
}

\section{Indigenous Peoples and the Refusal of the Market}

\author{
Rita ALCIDA RAMOS ${ }^{1}$ \\ Universidad de Brasilia (Brasil) \\ arramos@unb.br
}

Recibido: 31 de enero de 2014

Aceptado: 14 de junio de 2014

\begin{abstract}
Resumen
Al trabajar el tema del desarrollo y la interculturalidad, la antropología, con su experiencia centenaria en buscar la comprensión de mundos no occidentales, tiene el deber incontestable de 1) interrogar la validez universal de expresiones como ésas, principalmente cuando se transforman en productos de exportación, $y, 2$ ) traer al terreno de discusión ejemplos no occidentales que refuten, reduzcan, amplíen o, de preferencia, dialoguen con tales conceptos. Este trabajo presenta situaciones extraídas de diversos contextos indígenas con el fin de a) mostrar cómo la definición canónica de desarrollo puede ser inadecuada para experiencias indígenas que involucran recursos y riquezas, $\mathrm{y}, \mathrm{b}$ ) argumentar que el concepto de interculturalidad sólo le hace justicia a su propio nombre cuando promueve un ecumenismo de ideas y prácticas sobre el bien común, escapando, así, de modismos y premisas ideológicas no siempre étnicamente justas.
\end{abstract}

Palabras clave: Pueblos Indígenas; Críticas al Desarrollo; Interculturalidad; Ecumenismo.

\begin{abstract}
When working with development and interculturality, anthropology, with its long experience of trying to understand the non-Western world, must 1) ask about the universal validity of such terms, especially when they become export products, and 2) bring into discussion nonWestern examples that refute, reduce, enlarge or, preferably, dialogue with these concepts. Therefore, this paper presents situations from various indigenous contexts in order a) to show how the canonic definition of development can be inadequate to indigenous experiences involving resources and wealth, and b) to argue that the concept of interculturality can only do justice to its name when it promotes an ecumenism of ideas and practices about the common good, thus dodging fads and ideological premises not always ethnically fair.
\end{abstract}

Keywords: Indigenous Peoples; Critique of Development; Interculturality; Ecumenism.

Referencia normalizada: Alcida Ramos, R. (2014). Pueblos indígenas y el rechazo al mercado. Revista de Antropología Social, 23, pp. 29-53.

${ }^{1}$ Agradezco a Luis Cayón por sus comentarios y por la traducción del original en portugués. 
SUMARIO: 1. Desarrollo versus encantamiento. 2. Cómo los indígenas de la Amazonia enfrentan al desarrollo. 2.1. Reciprocidad postergada. 2.2. La curación del mundo. $2.3 \mathrm{El}$ conflicto de las lógicas económicas. 2.4. Emprendedores ascéticos. 3. Elementos comunes en las visiones indígenas sobre el desarrollo. 4. Los equívocos de la sostenibilidad y de la interculturalidad. 5. Finalmente. 6. Referencias bibliográficas.

Dame una hebra de tu cabello y te diré quien eres (Perrot, Rist y Sabelli, 1992: 11)

Nosotros, los Pueblos Indígenas, caminamos hacia el futuro por el rastro de nuestros antepasados Declaración Kari-Oca (Posey y Dutfield, 1996: 189)

\section{Desarrollo versus encantamiento}

Con su experiencia centenaria en buscar la comprensión de mundos no occidentales, la Antropología, al abordar temas como desarrollo e interculturalidad, tiene el deber incontestable de interrogar la validez universal de expresiones como esas, principalmente cuando se transforman en productos de exportación, y traer al campo de discusión ejemplos no occidentales que refuten, reduzcan, amplíen o, preferentemente, dialoguen con tales conceptos. Por lo tanto, este trabajo tiene el objetivo de presentar situaciones extraídas de diversos contextos indígenas para mostrar cómo la definición canónica de desarrollo puede ser inadecuada cuando se trata de experiencias indígenas que involucran recursos y riquezas. También pretende, aunque de manera sucinta y aplicando las mismas críticas dirigidas a la noción de desarrollo, argumentar que el concepto de interculturalidad sólo le hace justicia a su propio nombre cuando promueve un ecumenismo de ideas y prácticas sobre el bien común, escapando, así, de modismos y premisas ideológicas no siempre justas en términos étnicos.

La teoría y la práctica antropológica le dieron a la disciplina la atribución de desafiar al status quo al cuestionar la validez universal de algunas afirmaciones provenientes de una tradición sumamente etnocéntrica, si no racista. El desarrollo es uno de los campos en el que más se propagan las ideas recibidas a lo largo de generaciones desinformadas sobre el mundo indígena, ya sea por ignorancia o por demostración de poder. Como reconoce una antropología honesta, buscamos en el propio mundo indígena los antídotos contra esos venenos conceptuales e ideológicos que hacen del planeta un inmenso campo de refugiados culturales sin voz ni voto, rehenes de los caprichos del Estado, de la Modernidad y del Mercado. En esa búsqueda etnográfica, encontramos diversas posiciones de los indígenas, aunque convergentes, como la de los activistas Myrna Cunningham y Dennis Mairena de Nicaragua:

Un equívoco común es el de definir el desarrollo en términos de productividad creciente, modernización, tecnología y acumulación de riqueza. Esta es vista como la 
posesión y el cúmulo de bienes materiales. Tal concepto de desarrollo es exógeno para los pueblos indígenas (Cunningham y Mairena, 2009: 8);

en la ponderación de Gersem Luciano, de la etnia Baniwa del Noroeste brasilero:

La cuestión principal no es aceptar o negar el modelo actual de los proyectos de desarrollo impuestos por el Estado sino transformarlos en aquello que los pueblos indígenas contemporáneos quieren; no se trata de acabar con el desarrollo sino de indigenizarlo (Baniwa 2009: 7)

en la elocuencia de la boliviana Silvia Rivera Cusicanqui:

[La raíz de la fuerza aymara y quechua en Bolivia está en] el ser ocupantes milenarios de un espacio, el haberlo nombrado, ritualizado y convertido en espacio cultural y productivo a fuerza de fiestas, trabajos comunitarios, inventiva cultural y tecnología propia, todo ello, a pesar del acoso de la falacia modernizadora que sólo ha engendrado pobreza y truncado procesos de autonomía y autogestión productiva y política en vastas áreas del territorio patrio (Rivera, 2010: 29).

Estas tres visiones de desarrollo son diferentes pero tienen un fuerte denominador común, o sea: los proyectos de desarrollo, insensibles a las lógicas indígenas locales, insertos en los moldes occidentales, ya traen el propio fracaso en su interior, justamente por darle la espalda a las diferencias socioculturales que caracterizan a los pueblos involucrados en los proyectos. Esto hace que el éxito de la exportación del desarrollo sea una misión virtualmente imposible y, en la gran mayoría de los casos, indeseable en su aspecto globalizante y refractario a inflexiones locales. Si un proyecto no funciona, por más caro que sea, la culpa se le atribuye a la "resistencia al cambio", como se decía en las décadas de 1950 y 1960, pero nunca a la soberbia de la estructura top down que genera malentendidos y callejones sin salida, con frecuencia, funestos. Como una profecía auto-realizable, el idioma del desarrollo se construye alrededor de "valores inmutables", en la expresión de Gilbert Rist (1997: 10). No obstante, y aún citando a este autor, "si el 'desarrollo' fuera apenas una palabra útil para la suma de las aspiraciones humanas, podemos concluir que éste ¡no existe en ningún lugar y probablemente nunca existirá!’ (Rist, 1997: 10, énfasis en el original). La noción de valor está agregada al desarrollo y, como tal, adquirió el estatus de creencia en Occidente. No es por casualidad que el valor, asociado al desarrollo y al aparato lingüístico-ideológico que lo sustenta, ha sido descrito como la mitología programada del mundo moderno (Perrot, Rist y Sabelli, 1992).

Tendríamos aquí una aportación weberiana. Max Weber, en un comentario que no deja de tener cierto tono evolucionista, describió el largo proceso de secularización en Europa como un alejamiento del mundo místico e irracional que por

${ }^{2}$ La indigenización del desarrollo ha sido una expresión relativamente corriente, en especial en los estudios llamados postmodernos. Me alejo de la aplicación del término usado por Marshall Sahlins (2000), por ejemplo, cuando focalizo mi atención en los efectos de esa indigenización, no en el mundo globalizado sino en las realidades locales, como en los ejemplos aquí presentados. 
entonces reinaba. Lo que él llamó desencantamiento del mundo se refiere al creciente descreimiento en entidades supra-humanas, a las cuales recurrían los pueblos arcaicos en medio de un supuesto vacío de racionalidad. Tal y como señala Weber:

"A medida que el intelectualismo suprime la creencia en la magia, los procesos del
mundo se desencantan, pierden su valor mágico y, por lo tanto, simplemente 'son'
o 'ocurren', pero no significan nada más. En consecuencia, comienza a haber una
demanda creciente para que el mundo y el modelo total de vida quede sujeto a otro
orden que tiene valor y significado (Weber, 1978: 506).

Sin embargo, como el propio Weber admite, ciertos sectores intelectuales desilusionados con el status quo, se retrajeron del proceso de modernización y pasaron a venerar la ciencia como si fuera "el posible creador o al menos el profeta de la revolución social" (Weber, 1978: 514).

Ahora bien, si la noción de progreso y su pareja privilegiada, el desarrollo, son un subproducto de la ciencia y uno de los valores más vigorosos de la modernidad occidental, y si ese valor tiene la omnipotencia y la omnisciencia de lo absoluto, estamos frente a un proceso de reencantamiento del mundo que tiene, entonces, al progreso y al desarrollo como substitutos de la vieja Religión — con una universal $\mathrm{R}$ mayúscula—, a pesar de que las religiones — con una específica $\mathrm{r}$ minúsculacontinuaran creciendo tanto en Europa como en el resto del mundo. El propio Weber cuestiona: "¿ese proceso de desencantamiento, realizado a lo largo de milenios de civilización occidental y, en términos generales, ese 'progreso' del cual participa la ciencia como elemento y motor, tiene alguna significación que sobrepase esa pura práctica y esa pura teoría?" (Weber, 1970: 31). En fin, el desencantamiento weberiano ha sido duramente cuestionado y ahora se habla claramente del reencantamiento del mundo (Landy y Saler, 2009; Berman, 1981).

Entonces, ¿cómo reaccionan los pueblos indígenas — que además ya fueron rotulados como "hordas fetichistas" por el positivismo comteano (Gagliardi, 1989; Souza Lima, 1995) - a esos complejos procesos de desencantamiento y reencantamiento del mundo de los blancos? Creo que podríamos arriesgarnos y afirmar que los blancos nunca se presentaron a los indígenas como seres desencantados, como campeones de la razón y el secularismo. Al contrario, en muchos casos, ellos surgen como fuentes de desequilibrio en la forma de objetos, palabras y hechos que requieren de un intenso trabajo simbólico de depuración antes de entrar en el cotidiano indígena, como es extensamente demostrado en el libro Pacificando o Branco (Albert y Ramos, 2000).

Así, si la fuerza motriz occidental reposa en el triángulo ciencia-progreso-desarrollo, ésta se desvanece en el aire al llegar a los pueblos indígenas. De hecho, ellos están desencantados del desarrollo al experimentar directa o indirectamente sus efectos. Tal vez, más que nadie, los pueblos indígenas han tenido el dudoso privilegio de mirar de frente a la cara monstruosa de la quimera del desarrollo al ver el pillaje descarado de sus recursos naturales, de sus sistemas de conocimiento vilmente apropiados, de su salud y bienestar aplastados por intereses meramente mercantiles, sin ningún compromiso con la lógica de vida indígena. El desencantamiento del 
mundo de los blancos es una constante en la experiencia vivida y pensada por los pueblos indígenas desde el siglo XVI. Los largos milenios de civilización indígena anteriores a la invasión europea al Nuevo Mundo no los prepararon lo suficiente para enfrentar la creencia occidental en el papel auto-atribuido de ser el emisario de la verdad divina cuyo acto de fe es el sempiterno desarrollo. En nombre de ese desarrollo esquivo, todo lo pueden, todo lo hacen.

No obstante, el contexto indígena es el que más ha producido evidencias de la inoperancia de los intentos de desarrollo y de sus resultados desastrosos - carreteras que desgarran la selva sin llegar a ningún destino, proyectos indefendibles de colonización, hidroeléctricas que no producen energía, monocultivos que conducen al hambre. Al mismo tiempo, éstos ofrecen oportunidades para desmitificar la creencia en el desarrollo, desnudando sus dogmas, sus sectas, sus seguidores, etc. En este sentido, los pueblos indígenas están a la vanguardia de la desilusión que, aparentemente paradójica pero dialécticamente previsible, ya hace parte del propio proyecto desarrollista. Por otro lado, en el campo del desarrollo - y en especial en el del etnodesarrollo- es que los pueblos indígenas traen de vuelta el reencantamiento al inyectar sus creencias, sus profecías, sus saberes y sus temores en proyectos desarrollistas. Ellos son quienes están re-encantando el mundo de los blancos que los invade.

Con una dosis sustancial de ironía, Gilbert Rist se refiere así a los agentes de desarrollo - especialistas en economía-: "Su autoridad no depende tanto de resultados sino del cuidado que tienen en cumplir sus obligaciones" (Rist, 1997: 23), lo cual suena de manera inquietantemente semejante a las breves misiones evangelizadoras en las que se administran los sacramentos de manera automática, donde importa menos la eficacia de la misa que ejecutar los procedimientos litúrgicos. Rist, que defiende la convicción de que el desarrollo fue hecho para no tener éxito y le confiere el estatus de religión para Occidente, va más lejos:

Así como los cristianos conocen los innumerables crímenes practicados en nombre de su fe y a pesar de ello continúan apoyándola, también los especialistas en 'desarrollo' reconocen cada vez más los errores sin cuestionar las razones que los llevan a alistarse en éste. La creencia está hecha de tal modo que puede aguantar contradicciones fácilmente (Rist, 1997: 23).

\section{Cómo los indígenas de la Amazonia enfrentan al desarrollo}

A continuación presento cuatro situaciones en las que "tradición" y "modernidad" pasan por el tamiz de construcciones y deconstrucciones indígenas en el contexto de la Amazonia ${ }^{3}$. Veremos que hay una serie de puntos comunes que recorren

${ }^{3}$ Esos cuatro casos corresponden a las áreas que son objeto del proyecto de investigación "Pueblos Indígenas, Fronteras y Políticas Nacionales" financiado por el Consejo Nacional de Desarrollo Científico y Tecnológico (CNPq) de Brasil, y dividido en cuatro subproyectos: "Los Ashaninka en la frontera Brasil-Perú" a cargo del Dr. José Pimenta, "Los pueblos Tukano en la fontera colombo-brasilera" del Dr. Luis Cayón, "Los Ye'kuana en la frontera binacional: estrategias y políticas étnicas de transformación" (frontera Brasil-Venezuela) de la Dra. Karenina Andrade, y "El oro y el otro: políticas públicas y minería en la Tierra Indígena Yanomami” (frontera Brasil-Venezuela) del Dr. Rogério do Pateo (este último caso fue excluido aquí por no tener 
los cuatro casos y cómo cada contexto genera sus propias respuestas por parte de los indígenas involucrados. Diríamos que son casos paradigmáticos de esta nueva era del indigenismo ${ }^{4}$ en el que el supuesto aislamiento de los pueblos indígenas de la Amazonia muestra su doble cara de romanticismo mistificador y de insolencia dominadora. La ideología que se propaga por algunos sectores de la nación brasilera quiere, como se dice en inglés, comer y tener la torta al mismo tiempo (eat the cake and have it too), o sea, alejar el "problema indígena" para la inaccesible y recóndita selva amazónica y, al mismo tiempo, usurpar las tierras indígenas en nombre de un desarrollo escurridizo, ilusorio y, en consecuencia, inoperante.

\subsection{Reciprocidad postergada}

Comencemos con el análisis vigoroso de Gersem Baniwa, doctor en antropología, profesor de la Universidad Federal de Amazonas y perteneciente a la etnia Baniwa de la región del Vaupés, en el Alto río Negro, Noroeste de la Amazonia brasilera. El título de su disertación de maestría contiene en una cápsula el tema y el abordaje del autor: "Proyecto es como blanco trabaja: los líderes indígenas que se las arreglen para aprender y enseñarnos" (Baniwa, 2006). Esta es la cita-síntesis de un indígena de la región que denuncia el desequilibrio de fuerzas contenido en la noción de proyecto de desarrollo. Es frecuente en el texto, que el autor aclare que no está contra el desarrollo, pero señala firmemente la manera inadecuada como el Estado brasilero impone acciones y actitudes que pretenden doblegar a los indígenas a la manera occidental de practicar el desarrollismo, o sea, por un único camino, "el camino del mercado" (Baniwa, 2006: 44). Desde que los deseos indígenas han sido observados, Baniwa considera que el desarrollo puede ser hasta una necesidad ineludible para sus coterráneos después de que sufrieron la colosal influencia misionera de los salesianos por más de un siglo, quienes los empobrecieron culturalmente al infundirles las ideas básicas de una sociedad que, encima de todo, cree en el progreso y la riqueza material. En los internados salesianos, los indígenas del Alto río Negro - en su mayoría hablantes de lenguas tukano y arawak - recibieron una educación que sin ser laica fue eficaz en transmitirles conocimientos sólidos de lengua portuguesa y de otros campos del saber. Esa educación - que Baniwa prefiere llamar instrucción, una vez que educación es la transmisión de principios y valores a cargo de la familia extensa - sometió a los jóvenes indígenas a un régimen austero y orientado hacia la asimilación. A pesar de ello, dialécticamente, ese mismo

relevancia directa con el presente trabajo). Con excepción del primer caso, el del Alto río Negro brasilero, los análisis presentados corresponden a trabajos anteriores de estos investigadores en sus respectivas áreas de actuación.

${ }^{4}$ Me refiero al indigenismo como un amplio fenómeno político que no se limita al campo de las políticas estatales o privadas sobre la "cuestión indígena" sino que incluye, por ejemplo, las imágenes del indio creadas por los medios de comunicación de masas, por los trabajos de ficción, por la actuación de misioneros, por los activistas de los derechos humanos, por los análisis antropológicos y por las posiciones de los propios indígenas sobre la construcción de esas imágenes. Se trata de un aparato ideológico sobre las diferencias socioculturales en el interior del Estado-nación (Ramos, 1998: 6-7) y que podría denominarse Orientalismo Americano (Ramos, 2011), siguiendo el ejemplo de Orientalism de Edward Said (1979). 
régimen escolar los equipó con instrumentos que más tarde les fueron muy útiles en la defensa de su autonomía y derechos étnicos, como manda la Constitución del país. Sin embargo, hay que enfatizar que las escuelas salesianas, por más que intentaron, no formaron "brasileños genéricos" sino que acabaron reforzando el deseo de fortalecer su especificidad cultural. Hoy, los indígenas del Alto río Negro son uno de los grupos mejor preparados para enfrentar las vicisitudes del intenso contacto con la sociedad regional y, más ampliamente, nacional.

Baniwa expone que "las dificultades enfrentadas por los pueblos indígenas en la gestión de proyectos y programas son resultado de desencuentros entre realidades y racionalidades distintas: entre el entendimiento que se tiene de políticas de desarrollo por parte de los planificadores y de los diferentes horizontes socioculturales de los pueblos indígenas" (Baniwa, 2006: 12). Con admirable lucidez, su análisis va desenrollando la larga madeja de esos desencuentros que, en la mayoría de las veces, no son percibidos por los agentes del desarrollo como desencuentros en que ellos mismos son parte del problema, sino apenas como ignorancia o intransigencia de los indígenas. El centro de su análisis son los proyectos de desarrollo que comenzaron a atraer la atención local a partir de las libertades ciudadanas que la Constitución Nacional de 1988 garantizó a los pueblos indígenas ${ }^{5}$. El trabajo de deconstrucción semántica del concepto "proyecto" es uno de los puntos más relevantes del trabajo. El concepto "Proyecto", que normalmente entendemos como una virtualidad, gana cuerpo en la concepción indígena en aquella región de la Amazonia, un cuerpo con alma indígena: "los proyectos etnopolíticos de lucha por los derechos como la tierra, salud, educación y auto-sustento hacen parte de una estrategia de los indios para apropiarse de los instrumentos de poder de los blancos en favor de sus intereses presentes y futuros, idealizada y llevada a efecto por los actuales líderes indígenas" (Baniwa, 2006: 111). Todo esto parece resultar de la convicción indígena de que el "proyecto" es un "intercambio", un intercambio muy especial, al menos desde el punto de vista antropológico, como intentaré aclarar ahora, recurriendo al acervo mitológico del Alto río Negro y más allá en el mundo indígena suramericano.

Había una vez un demiurgo y su pueblo escogido. Al fundar el mundo social, el demiurgo le presenta al pueblo escogido la oportunidad de adoptar una serie de bienes que formarían su base material: arcos, flechas, canoas, hamacas, ollas de barro, de un lado; escopetas, radios, aviones, utensilios de metal, de otro. Para sorpresa del demiurgo, el pueblo escogido, sin saber qué dosis de poder acompañaba cada serie, optó por la primera, mientras que la segunda, como una sobra, le fue dada a otro pueblo, los blancos. Hoy, conscientes del poder que aquella parafernalia rechazada le confirió a los blancos, los pueblos indígenas del Alto río Negro consideran que su desprendimiento mítico fue un obsequio que le dieron a los blancos en aquellos tiempos primordiales y que, ahora, los "proyectos" que los blancos les traen son

${ }^{5}$ La Constitución brasilera de 1988, llamada Constitución Ciudadana, fue promulgada para substituir a la anterior, aprobada durante el régimen militar (1964-1985). La nueva Constitución trajo a los indios una serie de libertades en el sentido de garantizar tanto sus derechos territoriales y culturales como sus derechos jurídicos al eliminar, de juri más que de facto, la figura de la tutela. 
nada menos que el esperado acto de reciprocidad hace mucho tiempo postergado. Por lo tanto, cuando los críticos apuntan el carácter "paternalista" y "clientelista" de la mayoría de los proyectos de desarrollo en tierras indígenas, no conocen o toman en cuenta esa versión propia de los indios. Para los Baniwa,

esas nociones no se aplican, una vez que entienden ese tipo de relación nada más que como el deber y obligación de los jefes blancos, en la lógica de la reciprocidad y del carácter distributivo de bienes y servicios que caracteriza a la cultura baniwa, en la cual la contrapartida de los indios es la causa indígena en sí misma, el voto que elige a los jefes políticos y el don concedido por los dioses baniwa, desde el origen del mundo, para que los blancos fueran técnicamente más fuertes (Baniwa, 2006: 125).

Además, "proyecto" "es traducido como trabajo, y desarrollo como mejora de vida" (Baniwa, 2006: 125). En los proyectos, los indígenas activan su resiliencia al lograr revertir las estrategias de los blancos en favor de la continuidad étnica, no siendo guiadas más por antiguas interpretaciones de orden mítico, sino a partir de nuevas reinterpretaciones, incorporando las innovaciones cosmológicas y cognitivas traídas por el mundo de los blancos. "El proyecto sólo es viable si nosotros no perdemos el control social sobre el proceso" (Baniwa, 2006: 12). Los proyectos, por lo tanto, serían mecanismos para alcanzar un nivel de vida satisfactorio en el presente más que en el futuro, o sea, su horizonte es el corto plazo, no la utopía. Su noción de realización humana no está en la acumulación de riqueza, sino en el bien-vivir del presente.

Esta noción implica otra que es muy característica de los pueblos indígenas, en especial, en la Amazonia. Me refiero a los riesgos de la acumulación de riqueza. En la literatura antropológica de la región, es corriente el registro de la generosidad como una de las virtudes superiores de esta sociedad. Acumular bienes atrae la atención de la comunidad, la cual reacciona a través de varios mecanismos de rechazo a la persona que acumula. Uno de esos mecanismos es la hechicería que llevaría la desgracia a la víctima, si no la muerte. No es diferente en el caso del Alto río Negro, donde los emprendedores locales, coordinadores de proyectos, en especial, se vuelven peligrosamente vulnerables, pues son vistos como gestores de grandes sumas de dinero, dinero que es considerado como personal y no comunal. La conexión entre los recursos que entran a las aldeas y los resultados de su aplicación sufre muchas mediaciones financieras y burocráticas que escapan a la gran mayoría de los residentes. La desconfianza que de ello resulta puede llevar a que los administradores indígenas de los proyectos tengan temor de ser envenenados, como relata un interlocutor de Gersem Baniwa: "uno consigue las cosas y tiene algunos parientes que creen que usted está andando fácil [con motor], ganando fácil, traen esas ideas junto con otras cosas, con amenazas de hechicería, de envenenamiento" (Baniwa, 2006: 135). Esa desigualdad económica es uno de los resultados más dramáticos de la entrada de recursos desproporcionados a la vida normal de las aldeas, vía proyectos de desarrollo. Por este motivo, muchos jóvenes se niegan a administrar los proyectos. En la raíz de esos problemas está la incompatibilidad de horizontes, pues los indígenas acumulan para redistribuir entre ellos, mientras que los blancos acumulan para alimentar el 
mercado y sus propias cuentas bancarias. Las acusaciones de hechicería, un tema clásico de la antropología, pasa a ser una eficaz máquina anti-desigualdad, un recurso preventivo contra la explotación de parientes por parientes (Rivière, 1970). Para agravar aún más ese dilema, tenemos el problema de las disputas por poder.

Los proyectos, independientemente de sus resultados efectivos, acaban casi siempre creando serios conflictos en las comunidades que generalmente no son consideradas en el ámbito de las planeaciones y de las evaluaciones técnicas, en la medida en que los indios nunca los revelan, por fuerza de la tradición, para no profundizar los conflictos internos (Baniwa, 2006: 134).

Ni el pregonado desarrollo sostenible da credibilidad al credo del desarrollo, pues "aunque amplió su matriz conceptual para incorporar la dimensión ambiental, pecó por incorporar poco o casi nada la dimensión cultural de lo grupos sociales... En la práctica, la noción de sostenibilidad ha sido apropiada y manipulada por los países centrales como forma de mantener sus intereses políticos y económicos a través de las intervenciones" (Baniwa, 2006: 48). Pero, a pesar de todo, Baniwa cree en la plausibilidad de tales proyectos desde que se explicite la "contradicción existente entre el discurso y la práctica de los proyectos, que requieren ser contemporizados en términos de lenguaje, conceptos y metodologías para, como dicen los indios, 'definir si los proyectos son o no nuestros, están o no están a nuestro servicio" (Baniwa, 2006: 136).

\subsection{La curación del mundo}

Del lado colombiano de la frontera con Brasil, también en la región del Vaupés, viven pueblos de diversas familias lingüísticas, como los Makuna, hablantes de una lengua tukano. Me apoyo en el trabajo de Luis Cayón (2012) para tejer una serie de consideraciones sobre el impacto y la crítica al desarrollo, sobre sus maneras propias para lidiar con éste, para rodear las dificultades que éste les aporta, y para entender los modos de interacción con los agentes blancos del desarrollo. Cito extensamente el artículo de Cayón para hacer justicia a la riqueza de datos y al refinamiento de la interpretación.

Al igual que en Brasil, la Constitución colombiana de 1991 marcó profundamente la relación de los indígenas con el Estado, y con otros agentes del indigenismo en ese país. Uno de los efectos del esfuerzo constituyente - del cual participó un importante líder indígena elegido para el Senado de la República (Muelas, 2012) fue la creación de las Entidades Territoriales Indígenas (ETIs) que le aseguran a los indígenas la propiedad colectiva de sus tierras (Resguardos), pero les delega directamente la tarea de administrar sus propios territorios y fomentar el "desarrollo" en ellos, bajo la designación amplia de Ordenamiento Territorial. Estos planes no son más que

planes de Desarrollo Integral ajustados a las características de cada pueblo indígena, el cual debe ser adoptado por sus miembros. Este Plan de Desarrollo tiene en cuenta los aspectos económicos, sociales, ambientales, geográficos y políticos, 
conforme a los usos, costumbres y cosmovisiones de cada pueblo (Rivera y Gómez en Cayón, 2012: 67).

Sin embargo, es importante resaltar que aunque las ETIs fueron creadas por la Constitución de 1991, éstas aún no fueron reglamentadas por la legislación ordinaria y, por lo tanto, apenas existen en el papel (Cayón, 2012: 67). No obstante, independientemente de esa reglamentación, el proceso de instalación de proyectos de desarrollo en los Resguardos indígenas continúa hoy, y ha llevado a los indios a realizar un gran esfuerzo organizativo en el intento de mantener su autonomía territorial y cultural. Ese esfuerzo por conjugar las políticas públicas con las propias, informadas por una cosmovisión muy distinta a la nacional, es calificado de "cosmopolítica" por Cayón, siguiendo la definición de Isabelle Stengers, según la cual ese concepto contribuye a entender "las articulaciones de que eventualmente son capaces los mundos múltiples y divergentes en mira de nuevos modos de coexistencia posibles, donde estos mundos están en pie de igualdad" (Cayón, 2012: 66).

Entre tanto, el Estado colombiano somete las ETIs a la Ley Orgánica de Ordenamiento Territorial y cualquiera de las acciones realizadas por los indígenas debe estar "en armonía con el Plan Nacional de Desarrollo" (Rojas en Cayón, 2012: 67). Temiendo que las decisiones estatales les fueran impuestas irremediablemente, los indígenas de la región del Vaupés colombiano crearon organizaciones denominadas Asociaciones de Autoridades Tradicionales Indígenas, entre las cuales se destaca la Asociación de Capitanes Indígenas del río Pirá-Paraná (ACAIPI) (Cayón, 2012: 66). De sus actividades surgió la figura del Plan de Vida, el proyecto indígena de confeccionar "un calendario ecológico para reivindicar y negociar su forma particular de vida frente a las políticas de desarrollo promovidas por los agentes del Estado" (Cayón, 2012: 66). Para esos agentes, el ordenamiento territorial en áreas indígenas busca incorporar los indios a la nación por medio de proyectos impuestos, ya que para merecer la propiedad de sus Resguardos, los indígenas serían obligados a acatar pasivamente esos proyectos estatales, en un intercambio francamente desigual. Por ello, las asociaciones indígenas decidieron elaborar planes de desarrollo propios para sus tierras, usando un lenguaje inteligible y aceptable a ojos de los blancos, pero que incluye dimensiones que sólo les importan a los indígenas. Con gran argucia y perspicacia, ellos supieron calibrar la extensión de la capacidad de entendimiento de los blancos y ajustaron sus planes de vida a las limitaciones de éstos. El calendario ecológico es uno de los resultados de esa proeza. Lejos de doblegarse a la voluntad intransigente del Estado, los indígenas colombianos sacaron provecho de las contradicciones contenidas en las políticas públicas y aprovecharon los intersticios abiertos por la norma nacional del ordenamiento territorial para "consolidar su autonomía y recuperar sus espacios tradicionales" (Cayón, 2012: 68). Sus Planes de Vida, de carácter cosmopolítico, se fundamentan en el devenir histórico de cada pueblo y en el fortalecimiento de sus "culturas". ACAIPI, de la cual hacen parte los Makuna, pasó a privilegiar el conocimiento tradicional de los chamanes y de otros sabios para dibujar mapas ecológico-culturales donde se localizan recursos naturales y simbólicos, lugares sagrados, etc. "[Entre] las novedades que ha traído 
la Asociación [...] están las de permitir que las autoridades tradicionales se encuentren cara a cara, conversen y tomen decisiones conjuntas, al tiempo que tienen un espacio de reflexión público sobre los asuntos interétnicos" (Cayón, 2012: 69). De ese modo, accionan y re-significan sus propios conceptos cosmológicos, en un tipo de "purificación" a la Latour (1994), para que sirvan como instrumentos útiles en las negociaciones con el Estado.

Parte de las contradicciones de los proyectos de nación está en la duplicidad con relación a la diversidad sociocultural de Colombia. Si, por un lado, el Estado se reconoce como pluriétnico, por otro, intenta ensombrecer las diferencias internas con una política de homogenización, vía un multiculturalismo mal aplicado. En un primer paso, el Estado se auto-atribuye el poder de reconocer quién es o no objeto de diferenciación étnica. En un segundo paso, bajo esa capa de pseudo-multiculturalismo, se engendra una falsa homogeneidad que entra en flagrante contradicción con el postulado de la plurietnicidad garantizada por la Constitución de 1991. En ese limbo de incompatibilidad lógica originado por un Estado central débil es que los Planes de Vida prosperan.

La cartografía de los territorios realizada por ACAIPI, mostrando sus recursos naturales y culturales, está lejos de someterse a los criterios estatales que esperan que el levantamiento indígena simplemente indique "los recursos naturales de sus territorios para ver las potencialidades productivas que, en el futuro, los propios indígenas deberán gerenciar en sus tierras y con ello obtendrán los recursos para adelantar proyectos de desarrollo, salud y educación" (Cayón, 2012: 67). Al contrario, ACAIPI insiste en que "su territorio está ordenado desde que los demiurgos Ayawa se lo entregaron y que la forma de administrarlo es mediante el conocimiento de "manejar el mundo desde otra dimensión para así obtener el bienestar de la naturaleza y de la humanidad". El proyecto de ACAIPI trae a la superficie elementos cruciales que no han merecido cualquier atención por parte de los agentes desarro1listas, mucho menos del Estado, a pesar de que éste firmó su compromiso con la diversidad cultural.

Los sitios sagrados tienen unos dueños sobrenaturales con los que los kumua (chamanes) se comunican, y [...] la buena comunicación entre ellos mantiene el orden dentro del territorio. Si se irrespeta a los dueños y a los lugares, surgen enfermedades y problemas, y por ello se oponen tajantemente a las posibilidades de realizar explotaciones mineras en su territorio (Cayón, 2012: 70-71).

El calendario ecológico es otro aspecto de los Planes de Vida que encierra una inmensa complejidad cosmológica que implica cantos, bailes y visiones alucinógenas vinculadas a actividades estacionales, siempre acompañadas de la necesidad de curaciones chamánicas para mantener el flujo de la vida en todas sus dimensiones. Un ejemplo del encadenamiento del conocimiento de los indígenas es descrito por Cayón de la siguiente forma:

saben que después de la fructificación de la pupuña (Bactris gasipaes), cuando las Pléyades se acercan al cénit, se produce una última subida de peces que indica el 
inicio de la estación lluviosa, cuyo momento inicial produce que las ranas comestibles üma canten durante una noche entera, y eso apunta que las frutas silvestres están listas para ser recolectadas y que los humanos pueden planear una de sus ceremonias con las flautas de yuruparí. Todos esos conocimientos "ecológicos", junto a los saberes minuciosos que tienen sobre los lugares y los seres no humanos (comportamiento, relaciones simbióticas, hábitos reproductivos, alimentación, etc.) están codificados en las fórmulas poéticas propias del lenguaje erudito de los kumua (Cayón, 2012: 71).

Conscientes de la incapacidad que los agentes del desarrollo tienen para entender tamaña sofisticación, los indígenas del Vaupés colombiano se esfuerzan por simplificar al máximo el lenguaje que utilizan en sus prácticas cosmopolíticas a favor de la inteligibilidad. Para ello, alternan sus conceptos propios con aquellos derivados de las especialidades occidentales, como de la geología y la ecología. Así, logran satisfacer a los agentes del desarrollo con sus mapas detallados y realzan sus posiciones para un desarrollo futuro en sus propios términos. Además, los Planes de Vida constituyen un sistema de traducción, ajustando su complejidad cultural a la limitada capacidad de entendimiento de los blancos. Como apunta Cayón, "los usos de conceptos cosmológicos traducidos, y a veces esencializados para un observador externo, se transforman en un puente de inteligibilidad indispensable para negociar realidades diferentes" (Cayón, 2012: 74). Y concluye:

\begin{abstract}
A la hora de la verdad, con conceptos como 'manejo del mundo' o 'calendario ecológico cultural', estos indígenas crean un espacio en el que reflexionan, contestan y reaccionan a la visión impositiva de los agentes y de las instituciones estatales que han tenido que aceptar. [...] Con ello, los indígenas tienen el comando sobre la cantidad de información que es necesaria y suficiente para ser entendida por su interlocutor, a la vez que intentan salvaguardarse de aquellos momentos en que los técnicos del Estado [...] analizan sus propuestas de Planes de Vida (Cayón, 2012: 74).
\end{abstract}

Es posible que el Vaupés colombiano represente uno de los ejemplos más brillantes de indigenización del desarrollo.

\title{
2.3 El conflicto de las lógicas económicas
}

El tercer caso que abordo involucra al pueblo Ashaninka de la frontera BrasilPerú, en especial, a los habitantes del río Amonia en el lado brasilero. El análisis de este caso fue realizado por el antropólogo José Pimenta de la Universidad de Brasilia, y abarca más de un siglo de contacto interétnico de ese pueblo, principalmente, a partir de las invasiones de madereros en la región amazónica del Alto Juruá.

Pueblo de lengua arawak, los Ashaninka brasileños pasaron por transformaciones drásticas en sus modos de vida a partir de la segunda mitad del siglo XX (Pimenta, 2002). Como respuesta a las invasiones de los madereros, ese pueblo dejó su forma tradicional de asentamiento en familias nucleares dispersas a lo largo de los ríos para reorganizarse en una única comunidad, Apiwtxa, concentrada en el extremo nororiental de su territorio para poder fiscalizar la entrada de extraños por los ríos brasileros (Pimenta, 2006). Para ello, contaron con el fuerte estímulo social 
y financiero de agentes del órgano federal de protección a los indios (FUNAI). En Apiwtxa está reunido el mayor número de Ashaninka del lado brasileño.

El proceso de unificación social y de reorganización económica de los Ashaninka nos trae una situación analíticamente fértil que podríamos denominar caso-límite en lo que concierne a las contradicciones que los indígenas enfrentan en su lucha por autonomía étnica e independencia económica. Esos indígenas se enfrentaron al dilema de mantener su estilo de vida tradicional y ser destruidos por los invasores, o adoptar un nuevo modelo como forma de librarse de estos últimos. La secuencia de acciones que ese proceso de cambio desencadenó, le ha traído a los Ashaninka nuevos elementos que los sorprenden y preocupan, como el choque entre la lógica del don y la lógica del mercado.

Una serie de factores externos a sus tradiciones - el extraordinario empeño de agentes de la FUNAI y el matrimonio de un gran líder con una mujer blanca de la región - fueron decisivos para deflagrar esa gran transformación en la vida de los Ashaninka del Amonia (Pimenta, 2002; 2006; 2008), comenzando con la transformación del sistema político. Con la creación de una única comunidad, la autoridad difusa de los cabezas de familia fue substituida por la figura de un líder más centralizador cuya influencia afecta a los aproximadamente 300 habitantes de la aldea Apiwtxa. Ese líder, reconocido como tal desde antes de los cambios, asumió el papel de coordinador de las acciones que condujeron a la expulsión de los invasores y a la reorganización de la vida comunitaria. La tierra fue legalmente demarcada y sólo faltaba buscar los medios para mantener la comunidad autónoma y autosuficiente económicamente. En la década de 1990 se creó una asociación con estatus de persona jurídica y que tiene el nombre de la aldea. Entonces, llegaron los proyectos: proyecto de cooperativa, proyecto de escuela, proyecto agroforestal, etc. Después de la instauración de la jefatura, de la instalación de la "comunidad" y de la creación de la asociación, el próximo paso hacia la nueva configuración socioeconómica fue la inauguración de la cooperativa, también en la década de 1990. De este modo, intentaron "participar de la economía de mercado y asegurar, al mismo tiempo, su reproducción física y cultural como pueblo indígena diferenciado" (Pimenta, 2006: 3). La cooperativa es especialmente importante para esta discusión.

Los recursos provenientes de un proyecto permitieron la creación de la cooperativa mediante la adquisición de los bienes industrializados necesarios para el pago a los indígenas que abastecieran, primero, productos agrícolas y, después de que esa alternativa se mostró inviable, artesanías para alimentar el mercado externo del exotismo. Hasta hoy, la cooperativa está a cargo de varios hijos de la pareja interétnica conocidos como la familia Pianko. Con una instrucción suficiente sobre el mundo de los blancos, ellos administran la cooperativa dentro de los moldes requeridos por la lógica del mercado, o sea, solamente quien lleve artesanías para vender en la cooperativa recibe un pago.

En un intento por amenizar el carácter mercantil de la cooperativa, ésta fue denominada recientemente como ayõpari, que designa el sistema tradicional de intercambio de los Ashaninka y que ellos mismos traducen como "mi amigo", "mi socio de intercambio" (Pimenta, 2008: 140). No obstante, la cuestión es mucho 
más compleja que la mera atribución de un nombre. El sistema mercantil que rige la cooperativa y que es tan celosamente preservado por los administradores ashaninka genera un gran descontento entre los miembros de la comunidad, quienes se quejan de lo que ven como intransigencia de los gestores y de las ventajas que los benefician, lo que Pimenta llama "una posición estructural" derivada del "sistema cooperativista de commodities" (Pimenta, 2006: 28). En una cadena de acontecimientos - creación de una jefatura, sedentarización en comunidad, instalación de la cooperativa - vemos el camino prácticamente inexorable para la formación de un capitalismo embrionario en el que despunta, clara y consistentemente, la desigualdad social (Pimenta, 2008). Entonces, podríamos decir, parafraseando a Durkheim acerca del fenómeno religioso, que el caso ashaninka es un ejemplo de las "formas elementales del sistema capitalista".

Un contraejemplo puede aclarar de manera más dramática ese camino. Kishare, un líder ashaninka según los moldes tradicionales, para quien la generosidad era un atributo fundamental en el ejercicio de la autoridad que atrae seguidores, viendo el éxito de los Pianko con su cooperativa, decidió crear una en su propia aldea fuera de la órbita de Apiwtxa. Consiguió recursos iniciales para aprovisionar la cooperativa de artículos de intercambio, y pasó a distribuirlos al vaivén de los pedidos de sus co-residentes y sin recibir ninguna contrapartida en artesanías o en otros bienes producidos por los indígenas. La generosidad de Kishare, que tanto agradó a sus parientes, fue vista por los blancos como un acto de desperdicio y, por eso, no dotaron más a la cooperativa que, previsiblemente, dejó de existir y, en consecuencia, su aldea quedó vacía. La suerte de Kishare no podría demostrar mejor la incompatibilidad entre don y mercado. "Kishare se aisló socialmente y se refugió en la selva donde pasaba días y noches, solitario, conversando con animales. Abandonado por sus seguidores [...] Kishare perdió las ganas de vivir, dejó de alimentarse, enfermó y se dejó morir" (Pimenta, 2006: 12).

Mientras eso ocurría, los residentes de Apiwtxa, comandados por la familia Pianko, se involucraron en diversos proyectos de desarrollo sostenible, unos abandonados, otros en suspenso y otros muy exitosos. El más conocido de esos proyectos se refiere a la comercialización de jabones artesanales y que les produjo grandes trastornos con sus socios comerciales debido a la disputa por derechos sobre los recursos naturales y los conocimientos tradicionales asociados (Pimenta, 2004; Pimenta y Moura, 2010). Una de las grandes ambiciones de los Ashaninka del río Amonia es difundir la necesidad de conservar la selva y buscar alternativas sostenibles de sustento entre los pueblos indígenas y no indígenas de la región. Por todo eso, los Ashaninka comenzaron a incorporar el arquetipo - tan apreciado por los ideólogos de la sostenibilidad - de "indios ecológicos" por excelencia (Pimenta, 2007: 633).

\subsection{Emprendedores ascéticos}

En el extremo norte de Brasil, en la frontera con Venezuela, vive el pueblo Ye'kuana, también conocido en la literatura etnográfica como Makiritare o Maiongong. Hablantes de una lengua caribe, los Ye'kuana son más numerosos en 
Venezuela, y en Brasil cuentan con cerca de 400 personas divididas en cuatro aldeas a lo largo de los ríos Auaris y Uraricoera, en el estado de Roraima. A diferencia de la mayoría de los pueblos indígenas, en la actualidad, los Ye'kuana en Brasil no son presionados en sus tierras por invasores, aunque hasta finales del siglo XIX sufrieron los horrores de la explotación del caucho en la Amazonia (Andrade, 2007). Sus vecinos inmediatos son los Sanumá, subgrupo Yanomami, con quienes trabaron diversas reyertas durante el siglo XX, hasta que estos se asentaron definitivamente en el valle del río Auaris (Ramos, 1980). El caso Ye'kuana fue descrito por Karenina Andrade, profesora de antropología de la Universidad Federal de Minas Gerais.

Una de las características más sobresalientes de los Ye'kuana brasileros es su sentido de independencia. Al contrario de los demás indígenas de Roraima, nunca se afiliaron a la organización más fuerte del estado, el Consejo Indígena de Roraima (CIR), habiendo creado recientemente su propia asociación. Antes de la catástrofe del caucho, los Ye'kuana eran los líderes de una gigantesca red de intercambio que involucraba a un gran número de pueblos indígenas - y más tarde a los propios invasores blancos- en la región del Macizo Guyanés, más específicamente en el Alto Orinoco (Arvelo-Jiménez, 2001; Arvelo-Jiménez y Biord, 1994; Arvelo-Jiménez, Morales y Biord, 1989). En la actualidad, sus aldeas en suelo brasileño hacen parte de la Tierra Indígena Yanomami, demarcada oficialmente en 1991 en medio de la mayor invasión de mineros ilegales en la historia de esa región.

Al contrario de los casos arriba relatados, los Ye'kuana no se adhirieron al mercado de proyectos y sus logros se deben, principalmente, a su propio esfuerzo siguiendo los dictámenes de su proyecto de vida, sin hacerle concesiones a ningún tipo de donadores. Así como sus vecinos Sanumá, los Ye'kuana no sufren la presión de colonos ni de otros invasores. El Estado brasilero se hace presente por medio de un pelotón de frontera, de un puesto de la FUNAI y de un puesto de salud. Con la expulsión de la gran mayoría de los mineros, la Tierra Indígena permanece libre de colonizadores permanentes, lo cual, le da a estos pueblos indígenas la rara oportunidad de decidir cuándo y cómo quieren mantener contacto con forasteros.

El ya proverbial sentido emprendedor de los Ye'kuana (Andrade, 2007; 2009) está directamente ligado a su cosmología, la cual tiene la forma de una profecía. Conocidos y admirados regionalmente como indios confiables, buenos trabajadores, los Ye'kuana se esmeran por mantener la calidad de sus productos, ya sea artesanías o harina de yuca, gracias a "su ética ascética del trabajo permanente, incesante" (Andrade, 2009: 142). Esa ética es alimentada por una profecía que hace parte del código moral ye'kuana conocido como wätunnä. Todas las normas de comportamiento apropiado, toda la historia del pueblo ye'kuana y todo el porvenir están contenidos en ese código. La profecía inscrita en wätunnä remite a la creencia en ciclos sucesivos del mundo. Ya hubo otros ciclos en el pasado, y el actual está bajo el poder de los blancos, pero esto no durará por mucho más tiempo pues ya hay señales claras de su fin. Los Ye'kuana, seguros de que en el próximo ciclo ellos serán los dueños del poder, necesitan prepararse con el máximo posible de conocimiento para no cometer los errores de los blancos, enfurecer al demiurgo y traer de nuevo el horror de otro fin del mundo. Esa preparación requiere un intenso y 
extenso aprendizaje: desde aprender con los animales, con los otros pueblos vecinos con quienes convivían en su inmensa red de intercambios, y hasta con la escuela de los blancos. La paradoja de la profecía es que el propio proceso de acumular conocimiento, especialmente de los blancos, ya va conduciendo a los Ye'kuana hacia la desaparición, pues cada vez más se están volviendo semejantes a los blancos porque han ido perdiendo sus características propias.

En ese proceso plenamente autónomo, los Ye'kuana forjaron una ética de trabajo y de sentido emprendedor que los hace un caso único en la etnografía de la Amazonia. En 1990, un incidente trágico en la aldea del Olomai, un afluente del río Auaris, que dejó dos ye'kuana y tres mineros muertos, así como algunos sanumá heridos, ejemplifica esa especificidad de los Ye'kuana. El motivo fue la desaparición de dos kilos y trescientos gramos de oro en poder de los mineros. Ese incidente sirvió para mostrar los contrastes entre los principales agentes durante la campaña del oro en la Tierra Indígena Yanomami, en las postrimerías de la década de 1980. Esa situación extrema de desencuentros culturales entre dos pueblos indígenas, mineros miserables y empresarios inescrupulosos puede caber en una cápsula: en medio del tiroteo que mató al líder ye'kuana del Olomai "encontramos el modo sanumá de adquirir [bienes] para distribuir, el modo minero de acumular para despilfarrar, el modo empresarial de acumular para reinvertir y exhibir, y el modo Maiongong [Ye'kuana] de acumular para racionalizar" (Ramos, 1996: 146). La fascinación que los bienes industrializados ejercen para los Sanumá no tienen otra razón de ser que el deber de incrementar y ampliar sus redes de relaciones sociales. La búsqueda desesperada de los mineros por un filón de oro está relacionada al deseo de derrochar la riqueza lo más rápido posible para que la suerte los continúe acompañando. La desidia de los empresarios — dueños de cantinas y de aviones al servicio de la mina - por la pérdida de aviones y pilotos hace parte de su ambición por enriquecer rápidamente para invertir más y exhibir su fortuna con ostentación. Los Ye'kuana tuvieron en el auge de la mina la rara oportunidad de acumular conocimiento - la lengua portuguesa, el valor del oro- y dinero para el bien de la comunidad y para cumplir la profecía de wätunnä. La trágica experiencia del Olomai reafirma la postura de los Ye'kuana frente a la vida: "Hay que rescatar el conocimiento que está disperso por los pueblos extranjeros, conocimiento que no se tiene tradicionalmente y es preciso acumular" (Andrade, 2009: 151). La adquisición de bienes no es, pues, motivada por la acumulación material sino por la necesidad de aprender con los blancos de los que provienen esos bienes. La fase del oro hasta les fue de utilidad en ese aprendizaje de la lengua portuguesa, de la forma de producción propia y de los dividendos que generaron a través de cobros de peaje para aviones y barcos, de pagos a guías, etc. El dinero producido en esas transacciones fue usado para comprar una casa en la ciudad de Boa Vista, donde sus estudiantes pudieron hospedarse mientras estudiaban allá, así como algunos microscopios utilizados en la lectura de láminas de malaria, que se propagaba por la región, motores fuera de borda, máquinas de costura, máquinas para rallar yuca, etc. Sin embargo, más que bienes materiales, hay una meta a ser alcanzada, conforme reza wätunnä: 
La ética ye'kuana los llevó - y todavía los lleva - a invertir el dinero obtenido a través del comercio, del oro y, más tarde, del trabajo remunerado, no sólo en el bienestar de la comunidad sino también en instrumentos que posibiliten la adquisición del conocimiento [...] el consumo es el medio para llegar a un fin: prepararse para el ciclo futuro profetizado por wätunnä. ¿Cómo? Adquiriendo el poder de los blancos que se manifiesta en la acumulación de bienes [...] la adquisición de bienes y la perspectiva de reinar en el próximo ciclo por la apropiación del poder de los blancos sólo es posible con la acumulación de conocimiento, aliado al trabajo (Andrade, 2009: 153).

Diferentemente de los Ashaninka, los Ye'kuana nunca crearon una cooperativa, siempre distribuyeron igualmente los bienes adquiridos y, en consecuencia, no entraron en el círculo vicioso del mercado que conduce a la desigualdad social interna. Como en sus viajes tradicionales de largo alcance en el pasado, el líder de la aldea "cuidaría del reparto de las mercancías" (Andrade, 2009: 137) obtenidas, así como también en la actualidad "el resultado de la acumulación de conocimiento y los bienes adquiridos a través del comercio debe ser accesible para todos" (Andrade, 2009: 151).

Después de tantas vicisitudes históricas con las olas de asaltos de invasores, con la atracción destructiva de las mercancías y, principalmente en Venezuela, con el asedio persistente de misioneros, es impresionante la resiliencia de los Ye'kuana en su determinación de no sucumbir al canto de sirenas occidental y respetar y practicar la "horizontalidad en las relaciones interétnicas mientras evaden la jerarquización vertical en un sólo movimiento etnopolítico con idénticos métodos e iguales mecanismos de lucha" (Arvelo-Jiménez, 2001: 19).

No obstante, un fenómeno inesperado está trayendo dudas a los Ye'kuana en Brasil. Se trata de una serie de suicidios entre los más jóvenes de ambos sexos que, hasta ahora, no tienen una causa o causas consensuales. Los Ye'kuana comentan entre sí que la escuela - un elemento de origen exógeno- es responsable por esas tragedias, en una clara versión del conflicto entre generaciones. Jóvenes imbuidos de nuevos conocimientos estarían comenzando a rebatir la autoridad de los más viejos. En algunos casos, percibiendo la reacción negativa de estos últimos a ciertas expectativas o actividades no indígenas, los jóvenes se sienten afectados en su dignidad, desafían a sus padres, abuelos y autoridades locales, y cometen o amenazan con suicidarse.

¿Éste será el límite de la profecía wätunnä más allá de la cual la posición ye'kuana en el próximo ciclo del mundo estará en riesgo?

\section{Elementos comunes en las visiones indígenas sobre el desarrollo}

Una mirada más detenida sobre los cuatro casos presentados arriba, revela que hay varios rasgos comunes en lo que se refiere a la problemática del desarrollo. Sin pretender agotarlos, expongo apenas algunos de los más evidentes, a saber: la fascinación por bienes de consumo; el repudio a la desigualdad; la aceptación limitada del desarrollo a través de la oferta y demanda de proyectos; la búsqueda de compatibilización, en las brechas del sistema dominante, entre la economía del don 
y la economía de mercado; la búsqueda por autonomía; la observación de que los conocimientos propios y apropiados estén a favor o en contra del desarrollo; la crítica al desarrollo sostenible por no tener en cuenta seriamente a esos conocimientos.

De una manera u otra, los bienes industrializados ejercen una fascinación sobre todos los pueblos aquí abordados. No obstante, no es una atracción que traiga consigo un cambio estructural de perspectiva en la relación entre humanos y objetos. De forma general, la acumulación indígena de bienes de consumo no tiene por objetivo la riqueza individual sino la redistribución comunal. Por ejemplo, la atracción por chaquiras en los intercambios con los blancos siempre es notable para quien visita a los pueblos indígenas. Sin embargo, la acumulación es prácticamente inexistente pues el destino de los bienes industrializados es el de extenderse por un espacio que va mucho más allá de los límites de determinada aldea. Los bienes industrializados son "domesticados" para obtener la condición apropiada de consumo por los indígenas (Albert y Ramos, 2000), de manera que pasen a entrar en el flujo habitual de los objetos en las aldeas. Muy apropiadamente, Stephen Hugh-Jones caracteriza el intercambio indígena como una especie de conmutador entre dos mundos. Él afirma que "el intercambio desempeña un papel clave en ese circuito [de bienes], ofreciendo tanto una bisagra entre dos economías [del don y de mercado] como la puerta por donde ellas se entrecruzan" (Hugh-Jones, 1992: 70).

El principio estructural de la igualdad económica es común a todos los casos aquí presentados, y está en franca contradicción con la desigualdad derivada de la concentración de riqueza. Cuando ésta se hace evidente, como entre los Ashaninka aquí descritos, comienzan a surgir desequilibrios sociales que perturban el orden existente. Este caso, que podemos ver como un contraejemplo, nos muestra cómo surgen esos desequilibrios causados por la concentración de bienes en una única familia, aunque sea de manera involuntaria. En el caso Ashaninka, la excepción que aclara la regla, el riesgo de la desigualdad social, conscientemente evitada, es una alerta sobre las contradicciones entre la economía del don y la economía de mercado; cómo convivir con ambas en el mismo ambiente social es el gran desafío de ese grupo ashaninka de Brasil. Como vimos en el caso Baniwa, la hechicería es el antídoto contra el consumismo individual. Gestores de proyectos que, como consecuencia de sus funciones, acaban usufructuando bienes que no están al alcance de la mayoría, sienten la presión igualitaria al temer los efectos de la hechicería contra ellos. A su vez, los Ye'kuana se atienen, como un ancla, a los principios ancestrales de la ética del trabajo ascético que los protege de la contaminación del individualismo consumista. No hay entre ellos quejas de desigualdad social ni de ataques de hechicería, tal vez porque todos los miembros de sus comunidades en Brasil comparten la misma doctrina ancestral que prevé la muerte y el resurgimiento de los Ye'kuana como los próximos dueños del poder del mundo.

En todos los casos aquí presentados y que, probablemente, no desentonan de la mayoría de pueblos indígenas de la Amazonia, no hay un rechazo sumario del desarrollo y sí un esfuerzo por moldearlo a su propio estilo de vida. Desde el final del siglo XX, el "mercado de proyectos" (Albert, 2000: 198) viene recubriendo a la Amazonia indígena con sumas considerables de recursos destinados, en especial, a 
actividades económicas. No obstante, la lógica de los proyectos choca con el modo de vida indígena, cuando las nuevas formas de trabajo, de asociación y de relaciones sociales desiguales son impuestas a los indígenas, llevando, con frecuencia, al fracaso de los emprendimientos. Gersem Baniwa (2009) discurre con amplitud sobre las contradicciones que los proyectos transfieren a las comunidades, justamente porque "los dueños de los proyectos", o sea, los donadores de los recursos desconocen o desconsideran aspectos de la vida indígena que contemplan planos de la realidad que van más allá de la mera transacción comercial: restricciones a ciertas formas de trabajo, interacción entre humanos y no humanos, obligaciones de parentesco ineludibles, etc. En suma, cuestiones prioritarias para los indígenas que suelen ser interpretadas como malversación de recursos financieros, favoritismo nepotista, desperdicio o simple ignorancia e ingenuidad en el manejo del dinero y de la burocracia. Ese conflicto de interpretaciones responde por una buena parte de los proyectos fracasados. Hay que destacar la actitud de los Makuna y sus vecinos en el Vaupés colombiano quienes, previendo esos malentendidos, supieron dosificar sus conocimientos propios a la capacidad de comprensión de los blancos. Así que lo que éstos podrían rotular como supersticiones y supercherías, los Makuna hablan de sabiduría ecológica. Sin embargo, el Estado produce continuamente malentendidos casuísticos, sobrecargando cada vez más los esfuerzos indígenas por llegar a una comprensión mutua (Cayón, 2013: 127-128). También aquí, los Ye'kuana escapan de la regla y se niegan a entrar en el mercado de proyectos, en especial, para fines económicos, pues han obtenido pequeños recursos para la compra de radioteléfonos que ayudan en la fiscalización del territorio indígena y para la reactivación de ceremonias hace mucho inactivas. No obstante, en lo que concierne a la posibilidad de volverse dependientes de recursos y consultores externos, la parsimonia ye'kuana les ha garantizado un alto grado de autonomía, algo poco común en la Amazonia. Comerciantes tradicionales por excelencia, esos argonautas de la Amazonia aplican racionalmente su experiencia histórica con la dependencia para saber evitarla en la actualidad.

\section{Los equívocos de la sostenibilidad y de la interculturalidad}

Sobre el argumento del contenido cultural del conocimiento, hay que insistir en el aspecto indivisible del legado cultural. Bajo la noción de territorialidad está un universo repleto de creencias, relaciones sociales y conocimiento práctico que integra a una sociedad dada. Este punto es recalcado repetidamente en los casos descritos arriba y, de hecho, por gente nativa de todo el mundo. De aquí que el conocimiento indígena no pueda transferirse mecánicamente de un tipo de sociedad a otro como si se tratara de una transfusión mental. Lo que probablemente ignora la gente de negocios, que expresa admiración por la forma sostenible con que los indígenas utilizan sus recursos, es que esta sabiduría involucra algo más que la simple identificación, descripción y utilización de la fauna y la flora. Tal conocimiento está ligado a cosmologías y estilos de vida tan diferentes de la forma de vida occidental que son tan indetectables como totalmente desconcertantes y prácticamente incompatibles con la vocación predatoria de las actividades industriales. Lo que frecuentemente es 
visto como costumbres extrañas - prohibiciones alimenticias, restricciones extranaturales a la cacería, pesca, etc., división del trabajo motivada por razones metafísicas, elaboración de rituales antes de actividades económicas - puede ser la piedra angular del conocimiento indígena. Los negocios, pragmáticos por definición, no logran armonizarse ni encajarse con las particularidades culturales de la vida nativa, lo que nos lleva a cuestionar si las demostraciones de respeto por la sabiduría indígena no son meras formalidades para satisfacer a lo políticamente correcto (Ramos, 2006: 257).

Por ejemplo, el tan problemático concepto de la espiritualidad, el cual no pasa por la barrera de la racionalidad y objetividad occidentales es, de hecho, una pieza clave para la comprensión del diversificado universo indígena (Ramos, 2014) . Como observó Darrell Posey, la espiritualidad "es la más elevada forma de conciencia y la conciencia espiritual es la forma más alta de entendimiento. En este sentido, el conocimiento tradicional no es conocimiento local sino una expresión del conocimiento universal expresado a través de lo local" (Posey, 2002: 28). Para el pensador tewa, Gregory Cajete, espíritu y espiritualidad no tienen nada que ver con religión sino con la búsqueda de la verdad o de las verdades: "La ciencia nativa, en sus niveles más altos de expresión, es un sistema de caminos para llegar a esa verdad perpetuamente en movimiento o "espíritu"' (Cajete, 2000: 19). La diferencia entre lenguaje literal y lenguaje simbólico pasa muy lejos de la capacidad occidental por entender la diversidad del pensamiento humano.

En defensa del etnodesarrollo, propio de los "grupos étnicos en el interior de sociedades más amplias", Rodolfo Stavenhagen propone que éste debe "volverse la cuestión principal de la reflexión sobre el desarrollo, tanto teórica como prácticamente" (Stavenhagen, 1985: 41). De hecho, a lo largo de los últimos treinta años, el desarrollo sostenible pasó de ser un deseo a una realidad, pero apenas bajo la forma de una ideología más de la modernidad. Ni Stavenhagen en los años 1980, ni los defensores actuales del etnodesarollo se preguntan lo principal, o al menos nada semejante a las duras críticas que le hacen los integrantes del grupo europeo que, significativamente, lleva la sigla M.A.U.S.S. (Movimiento Anti-Utilitarista en las Ciencias Sociales), en especial, Gilbert Rist (1997) y Dominique Perrot (1991), así como un número creciente de autores como James Fegurson (1994), Arturo Escobar (1995), Stuart Kirsch (2006), Henare (2005), para citar apenas a algunos. Rist, por ejemplo, afirma que "la ideología del 'desarrollo' entró al reino del oxímoron" (Rist, 1997: 174), aclarando que, en la literatura o en los textos místicos, esa figura retórica permite "decir lo indecible evocando la coincidencia de opuestos" (Rist, 1997: 174). En suma, el desarrollo es una imposibilidad práctica. Rist es igualmente escéptico con la noción de desarrollo sostenible y, con fina ironía, lo enmarca en el famoso dicho de un personaje de Lampedusa: "Las personas deben ser inducidas a pensar que todo está cambiando, de manera que todo permanezca como antes" (Rist, 1997: 182).

${ }^{6}$ Ver la excelente demostración etnográfica de Keith Basso (1996) sobre los Apache occidentales. 
Si entendemos por etnodesarrollo "el derecho de los grupos étnicos de participar (o no...) en sus propios términos del proceso moderno de desarrollo" (Kassam, 2002: 65), a la luz de los ejemplos aquí expuestos, no dejamos de darle la razón a Rist. "Los propios términos" de los pueblos indígenas, cuando no entran en conflicto directo con la (des)razón desarrollista —-miedo a la hechicería, rompimiento de relaciones igualitarias - exigen esfuerzos especiales - malabarismos lingüísticos, invisibilización social-, para no ser atropellados por ella. De la lógica del mercado a la lógica científica occidental, los indígenas acaban por remar contra la corriente consumista para mantener su autonomía y valorizar sus propios conocimientos. El desarrollo sostenible puede hasta ser exitoso en términos mercadológicos, como con los Ashaninka, pero el costo social tal vez sea demasiado alto para perdurar.

\section{Finalmente}

La falacia deductiva contenida en el primer epígrafe de este trabajo demuestra al mismo tiempo la arrogancia de una cierta visión sobre la ciencia occidental contemporánea y su incapacidad para sobrepasar el empirismo superficial. Más allá de una hebra de cabello conteniendo el ADN de alguien, hay un universo repleto de maneras diversas de ser, de saber y de hacer que hasta ahora se han mantenido rehenes de la ignorancia occidental, a pesar de que la genética moderna atribuya que el setenta u ochenta por ciento del comportamiento humano se debe no a los genes sino al medio ambiente, o, en términos antropológicos, a la cultura. La inapetencia occidental por el detalle y por el esfuerzo de llegar al entendimiento profundo de una realidad desconocida, combinada con el desequilibrio de poder global, ha sido una de las fuentes más dañinas de sufrimiento para los pueblos indígenas. Los efectos sociales y políticos de este méconnaissance, muchas veces cultivado, pueden ser devastadores, como nos muestra Emiko Ohnuki-Tierney en su sensible estudio sobre los pilotos kamikaze en la Segunda Guerra Mundial. Méconnaissance, dice la autora, "puede ocurrir cuando las partes involucradas no se dan cuenta de la falta de comunicación" (Ohnuki-Tierney, 2002: 3).

La noción de interculturalidad es subyacente a las consideraciones aquí señaladas con relación al conocimiento indígena, al desarrollo y a las frecuentes fallas de entendimiento mutuo en el mundo interétnico de la Amazonia. Muy en boga actualmente, en especial en el contexto geopolítico suramericano, la interculturalidad, por evocar algún tipo de equilibrio cultural y político, en realidad, puede ser una barrera más al entendimiento mutuo. Me temo que pueda crear más méconnaissance que diálogos equilibrados entre los Estados-nacionales y los pueblos indígenas. Una crítica de la interculturalidad apuntaría hacia los lugares estructuralmente diferentes de los agentes involucrados. Para que una genuina interculturalidad de hecho se materialice, será necesario que cada parte implicada tenga un acceso igual a los recursos lingüísticos, simbólicos y materiales de todas las otras. La interculturalidad sólo hará justicia a ese nombre cuando promueva el ecumenismo de ideas y prácticas sobre el bien común, escapando de modismos, premisas ideológicas y promesas políticas que no siempre son étnicamente apropiadas y justas. Los casos aquí presentados exponen algunas de esas premisas y señalan algunos obstáculos que 
persisten y pueden hacer del desarrollo una quimera, o, en la mejor de las hipótesis, una utopía que, como el propio nombre indica, está predestinada a no materializarse jamás.

\section{Referencias bibliográficas}

ALBERT, Bruce

2000 “Associações indígenas e desenvolvimento sustentável na Amazônia brasileira” en C.A. Ricardo (Comp), Povos Indígenas no Brasil 1996-2000. São Paulo: Instituto Socioambiental, 197-207.

ALBERT, Bruce; RAMOS, Alcida

2000 Pacificando o branco: Cosmologias do contato no Norte-Amazônico. São Paulo: Unesp.

ANDRADE, Karenina V.

2007 A ética Ye'kuana e o espírito do empreendimento. Tesis doctoral. Departamento de Antropologia. Universidade de Brasília.

2009 “Wätunnä: Tradição oral e empreendimentos econômicos dentre os Ye'kuana” en M.I. Smiljanic, J. Pimenta y S.G. Baines (Comps.), Faces da Indianidade. Curitiba: Nexo Design/Capes, 127-154.

ARVELO-JIMÉNEZ, Nelly

2001 "Movimientos etnopolíticos contemporaneos y sus raices organizacionales en el sistema de interdependencia regional del Orinoco" Série Antropologia, 309, Departamento de Antropologia, Universidade de Brasília, 1-24.

ARVELO-JIMÉNEZ, Nelly; BIORD, Horacio

1994 "The impact of conquest on contemporary indigenous peoples of the Guiana Shield" en A. Roosvelt (Comp.), Amazonian Indians from prehistory to the present. Tucson: University of Arizona Press, 55-78.

ARVELO-JIMÉNEZ, Nelly; MORALES MÉNDEZ, F.; BIORD CASTILLO, H.

1989 "Repensando la historia del Orinoco". Revista de Antropología, Universidad de los Andes, Colombia, 1-2: 155-174.

BANIWA, Gersem

2006 "Projeto é como branco trabalha; as lideranças que se virem para aprender e nos ensinar': Experiências dos povos indígenas do alto rio Negro". Dissertação de Mestrado, Departamento de Antropologia, Universidade de Brasília.

2009 "To dominate the system and not to be dominated by it" Poverty in Focus (International Policy Center for Inclusive Growth), 17: 6-8.

BASSO, Keith

1996 Wisdom sit in places: Landscape and language among the Western Apache. Albuquerque: University of New Mexico Press.

BERMAN, Morris.

1981 Reenchantment of the world. Ithaca: Cornell University Press. 
CAJETE, Gregory

2000 Native science: Natural laws of interdependence. Santa Fé, NM.: Clear Light.

CAYÓN, Luis

2012 "Plans de vie et gestion du monde: Cosmopolitique autochtone du développement en Amazonie colombienne". Recherches Amérindiennes au Québec, XLII (2-3): 63-77.

2013 Pienso, luego creo. La teoría makuna del mundo. Bogotá: Instituto Colombiano de Antropología e Historia.

CUNNINGHAM, Myrna; MAIRENA, Dennis

2009 "Laman Laka: If I have it you have it, if you have it I have it" Poverty in Focus (International Policy Center for Inclusive Growth), 17: 8-9.

ESCOBAR, Arturo

1995 Encoutering development: The making and unmaking of the Third World. Princeton: Princeton University Press.

FERGUSON, James

1994 The anti-politics machine: "Development," depoliticization, and bureaucratic power in Lesotho. Minneapolis: University of Minnesota Press.

GAGLIARDI, José M.

1989 O indígena e a República. São Paulo: Hucitec.

HENARE, Manuka

2005 "The implications of globalization for indigenous communities of New Zealand Aotearoa and elsewhere - A step towards Te Ao Mārama or towards Te Pō?" en R. Patman y C. Rudd (Comps), Sovereignty under siege?: Globalization and New Zealand. Hants, Inglaterra: Ashgate, 111-128.

HUGH-JONES, Stephen

1992 "Yesterday's luxuries, tomorrow's necessities: Business and barter in northwest Amazonia" en C. Humphrey y S. Hugh-Jones (Comps.), Barter, exchange and value: An anthropological approach. Cambridge: Cambridge University Press, 42-74.

KASSAM, Aneesa

2002 "Ethnotheory, ethnopraxis: Ethnodevelopment in the Oromia regional state of Ethiopia" en P. Sillitoe, A. Bicker y J. Pottier (Comps.), Participating in development: Approaches to indigenous knowledge. Londres: Routledge, 64-81.

KIRSCH, Stuart

2006 Reverse anthropology: Indigenous analysis of social and environmental relations in New Guinea. Stanford: Stanford University Press.

LANDY, Joshua; SALER, Michael

2009 The re-enchantment of the world: Secular magic in a rational age. Stanford: Stanford University Press. 
LATOUR, Bruno

1994 Jamais fomos modernos. Rio de Janeiro: Editora 34.

MUELAS HURTADO, Lorenzo

2012 "Os povos indígenas e a Constituição da Colômbia” en A.R. Ramos (Comp.), Constituições nacionais e povos indígenas. Belo Horizonte: Editora UFMG, 36-52.

OHNUKI-TIERNEY, Emiko

2002 Kamikaze, cherry blossoms, and nationalism: The militarization of aesthetics in Japanese history. Chicago: Chicago University Press.

PERROT, Dominique

1991 "Les empêcheurs de développer en rond" La fiction et la feinte: Développement et peuples autochtones, 13: 4-11.

PERROT, Dominique; RIST, Gilbert; SABELLI, Fabrizio.

1992 La mythologie programmée: L'économie des croyances dans la société moderne. Paris: Presses Universitaires de France.

PIMENTA, José

2002 'Índio não é todo igual': A construção ashaninka da história e da politica interétnica. Tesis doctoral. Departamento de Antropologia, Universidade de Brasília.

2004 "Desenvolvimento sustentável e povos indígenas: os paradoxos de um exemplo amazônico". Anuário Antropológico 2002/2003: 115-150.

2006 "Reciprocidade, mercado e desigualdade social entre os Ashaninka do Rio Amônia" Série Antropologia, 392: 34.

2007 "Indigenismo e ambientalismo na Amazônia ocidental: A propósito dos Ashaninka do rio Amônia". Revista de Antropologia, 50(2): 633-81.

2008 "'Viver em comunidade'. O processo de territorialização dos Ashaninka do rio Amônia”. Anuário Antropológico/2006: 117-150.

PIMENTA, José; MOURA, Guilherme

2010 "O sabonete da discórdia: Uma controvérsia sobre conhecimentos tradicionais indígenas" en M. Coelho de Souza y E.C. de Lima (Comps.), Conhecimento e cultura: Práticas de transformação no mundo indígena. Brasília: Athalaia Gráfica e Editora/ Capes, 63-93.

POSEY, Darrell

2002 "Upsetting the sacred balance: can the study of indigenous knowledge reflect cosmic connectedness?" en P. Sillitoe, A. Bicker y J. Pottier (Comps.), Participating in development: Approaches to indigenous knowledge. Londres: Routledge, 24-42.

POSEY, Darrell; DUTFIELD, Graham

1996 Beyond intellectual property: Toward traditional resource rights for indigenous peoples and local communities. Ottawa: International Development Research Center.

RAMOS, Alcida Rita

1980 Hierarquia e simbiose: Relações intertribais no Brasil. São Paulo: Hucitec. 
1996 “A profecia de um boato: Matando por ouro na área Yanomami”. Anuário Antropológico/95: 121-150.

1998 Indigenism: Ethnic Politics in Brazil. Madison: University of Wisconsin Press.

2006 "The commodification of the Indian" en D. Posey y M. Balick (Comps.) Human impacts on Amazonia: The role of traditional ecological knowledge in conservastion and development. Nueva York: Columbia University Press, 248-272.

2011 "Indigenismo, un orientalismo americano". Desacatos 39: 163-175.

2014 "Mentes indígenas y ecúmene antropológico" en D. Betrisey y S. Mereson (Comps.), Antropologías contemporáneas: Saberes, ejercicios y reflexiones Madrid: Miño y Dávila (en imprenta).

RIST, Gilbert

1997 The history of development from Western origins to global faith. Londres: Zed Books.

RIVERA CUCICANQUI, Silvia

2010 'Oprimidos pero no vencidos': Luchas del campesinato Aymara y Qhechwa 19001980. La Paz: La Mirada Salvaje.

RIVIÈRE, Peter

1970 "Factions and exclusions in two South American village systems" en M. Douglas, Witchcraft confessions and accusations. Londres: Tavistock, 245-255.

SAHLINS, Marshall

2000 Culture in practice. Nueva York: Zone Books.

SAID, Edward

1979 Orientalism. Nueva York: Vintage.

SOUZA LIMA, Antonio Carlos de

1995 Um grande cerco de paz: Poder tutelar, indianidade e formação do estado no Brasil. Petrópolis: Vozes.

STAVENHAGEN, Rodolfo

1985 "Etnodesenvolvimento: Uma dimensão ignorada no pensamento desenvolvimentista”. Anuário Antropológico/84: 11-44.

WEBER, Max

1970 Ciência e política: duas vocações. São Paulo: Cultrix.

1978 Economy and Society, Vol. 1. Berkeley: University of California Press. 